\title{
Language Use and Management in Mining Companies in the DRC
}

\section{Kalume Mambo ${ }^{1}$, Ngoloma Katsuva1, Nshindi Mulamba ${ }^{1}$, Hambye Phillipe², Kibamba Kyungu1, Mutombo Mukunda1}

${ }^{1}$ English Department, University of Lubumbashi, Lubumbashi, DRC

${ }^{2}$ French Department, Catholic University of Louvain, Louvain-la-Neuve, Belgium

Email: mambokalume@yahoo.com,narcissemk@yahoo.fr

How to cite this paper: Mambo, K., Katsuva, N., Mulamba, N., Phillipe, H., Kyungu, K. and Mukunda, M. (2018) Language Use and Management in Mining Companies in the DRC. Open Access Library Journal, 5: e4748.

https://doi.org/10.4236/oalib.1104748

Received: July 2, 2018

Accepted: August 20, 2018

Published: August 23, 2018

Copyright $\odot 2018$ by authors and Open Access Library Inc.

This work is licensed under the Creative Commons Attribution International License (CC BY 4.0).

http://creativecommons.org/licenses/by/4.0/

\section{Open Access}

\begin{abstract}
This paper aims at highlighting how English is gaining momentum on tiptoe in the Democratic Republic of Congo through mining companies as its gateways, although the country traditionally belongs to Kachru's Expanding Circle, and to which extent these mining companies, which to a large extent are branches of multinational companies, cope with language use and management within multilingual workplaces. The insights gained from various companies demonstrate that the adoption of English alone as a corporate language is not enough and that multilingual communication would be the best practice to overcome language barriers within these workplaces.
\end{abstract}

\section{Subject Areas}

Linguistics

\section{Keywords}

Language Use and Management, Mining Companies, Multinational

Companies, DRC

\section{Introduction}

A glance at the actual sociolinguistic situation of the Democratic Republic of Congo (DRC) reveals that today more than ever before English is gaining ground on tiptoe through mining companies where it is used as a working language in a country which traditionally belongs to Katchru's Expanding Circle and where French, the official language, shares some functions with the four national languages.

The fact is that most of the mining companies operating in the DRC today are 
branches of multinational mining companies. In order to grasp the context in which these mining companies operate and how the issue of language is tackled, it is essential to gain some insights from multinational companies which are de facto multilingual organizations which bring together people from different cultural backgrounds who must work together towards the success of a common organizational mission. The issue of language use and management in multilingual settings needs to be addressed because little academic research has been conducted on language in multinational corporations which are multilingual communities worthy of academic investigation.

\section{Language Use in Multinational Companies}

It is widely agreed that during the past decades the role of language in international business was forgotten and neglected. As a matter of fact, language was deemed to be "the most neglected field in management" by Reeves and Wright [1], "the forgotten factor in Multinational Management" by Marschan-Piekkari et al. [2] and "the orphan of International Business Research" by Feely and Harzing [3].

This shadow role of language in international business is evidenced by the paucity and scarcity of research in language issues in business and occupational settings.

Today, however, more than ever before, with the increased globalization of business and economy, of which the recent phase dates back to the 1980s [4], and of which Multinational Companies are an outgrowth, the role of language has become central for efficiency in communication and cost-effectiveness of productivity in multilingual environments.

It is in this vein that Dhir and Goke-Pariola [5] argue that with increased globalization of business and economy, corporations are paying greater attention to the languages in which they conduct their business. They further assert that businesses that operate globally bring together people with different cultural orientations and who do not all speak the same languages, but who work toward a common organizational mission. Language therefore affects the ability of Multinational Organizations to function in the global markets.

In line with this argument, Heller [6], on the other hand, points out that "one of the major features of the new economy (globalized) is the central role that language plays as a means of production and as a product itself".

In other words, in the new economy, language has become a commodity, an asset, and a capital. Instead of selling their physical strength as it was the case in former times for landing a job, today people are selling their communicative skills. Language has thus acquired an economic value [7]. Like money, it is an asset, and when in use, it is a capital [5].

Yet, the challenge facing Multinational Companies and preventing them from operating efficiently in global workplaces is the language barrier through linguistic diversity. Indeed, language barrier generally triggers negative conse- 
quences including misunderstandings, discrimination, anxiety, vague instructions, incorrect execution of instructions, frustration, exclusion, interpersonal conflicts, waste of time, money, and efforts, malaise, stress, aggressiveness, mistrust, linguistic insecurity, suspicion, irritation, isolation, friction, dissatisfaction, low morale, and health and safety hazards. These consequences are likely to impact negatively on efficiency, cost-effectiveness, safety, and above all, on productivity in the workplaces.

In order to reduce these negative effects of language barrier through language diversity, multinational companies have formulated language policies, that is, formal ways to decide which language is used in corporate communication [8].

With regard to language policies, Dhir and Goke-Pariola [5] point out that one of the challenges in formulating a corporate language policy is the difference in goals and attitudes between corporate planners and sociolinguists and how they view language and the goals of language planning. They specify that a corporate planner's mission is to maximize the organization's competitive advantage within the strategic environment in which it operates. Hence, the management of an organization would seek to adopt for its organization a working language that best enables it to fulfill this mission. On the other hand, a sociolinguist's mission is to maximize the quality and quantity of social interactions within the society defined by the multinational organization interactions.

With regard to language use, a corporate planner seeks to choose a working language while the sociolinguist seeks to study community languages.

In most cases, the main language policy prevailing in a great number of multinational companies consists in the adoption of English as the corporate language owing to its recognition as a global language of international business.

As Harzing and Pudelko [9] indicate, English is naturally used as a corporate language in all of the English-speaking multinational companies and is likely to be the default language in these companies even if they do not have a corporate language.

Admittedly, the need to communicate effectively within multinational companies requires some commonality in order to reduce language barriers. The adoption of English as a corporate language is therefore thought to improve communication and remove language barriers by encouraging some linguistic homogeneity. Indeed, Marschan-Piekkari et al. [8] and Sorensen [10] argue that the corporate language is intended to increase efficiency by overcoming misunderstandings, reducing costs, avoiding time-consuming translations and creating "a sense of belonging to a global family" and "cohesion within the firms".

Miller and Jensen [11] also suggest that for multinational companies, efficiency of internal communication is seen to require a common language. They also argue that the use of a common language should be considered as one way of standardizing language diversity.

Kankaaranta and Louihiana-Salminen [12] argue that a common corporate language such as English tends to be perceived as a neutral language and emo- 
tionally charged with cultural identification.

Some common options for overcoming language problems within multilingual companies have been suggested by researchers, among whom Harzing et al. [13], namely:

1) Adoption of English as a common corporate language.

2) Adoption of multiple languages as corporate languages.

3) Reliance on translation/interpretation services.

4) Language training offered to staff, both local and expatriate.

5) Selective recruitment of personnel with language skills.

6) Use of language nodes (language intermediaries or language buddies).

7) Use of external language resources such as translators and interpreters.

8) Machine translation.

Each of the above options has its advantages and disadvantages.

With regard to these options, Grigore [14] suggests that there is no clear cut solution to the language problems companies are faced with and that the secret would perhaps be to find the best mix of solutions or, may be the best solutions are yet to be discovered, springing from a combination of the options presented above.

Yet, although the introduction of a corporate language is likely to facilitate communication, it will not render the firm monolingual, as Harzing and Pudelko [9] suggest, because language diversity is likely to persist.

Similarly, Tange and Lauring [15] argue that English is not a neutral language and as such its use may not overcome the language barrier within the multinational and multilingual corporation.

They further argue that the use of English as a corporate language may lead some employees to avoid contributing fully to knowledge sharing in their organizations because of a lack of confidence in their linguistic abilities in English. They have also identified negative effects like language clustering and thin communication.

Thomas [16] also asserts that "however, as important as English is for global communication, it is insufficient for the many communication needs at the local level".

Thomas further argues that it is generally agreed that in order to do business in a foreign country, especially one which speaks a different language or language variety, knowledge of the foreign language and culture is critical for success".

Didier-Cook et al. [17] also assert that not speaking the language of the host country is a lack of respect for the local people and culture.

Van den Born and Peltokorpi [18] on their side suggest that increasing knowledge about the host country culture and language facilitates adaptation and expatriates performance and is thus of key importance.

From the different opinions expressed above, it should be admitted that however important English is as a corporate language, its exclusive use is not a pa- 
nacea. English is not enough for all the situations. Other languages are also valuable. Multilingual communication should prevail because multinational companies are multilingual almost by their definition, as Luo and Shenkar [19] assert.

\section{Language Use and Management in Mining Companies in the DRC}

\subsection{Background}

It is worth recalling that the Democratic Republic of Congo has often been referred to as a "geological scandal" owing to the great number of mineral resources that its soil and sub-soil contain.

From the colonial period, mining activities have been historically operated by the Union Minière du Haut Katanga, the giant Belgian concessionary Company, from 1906 to 1967, then by Gécomin from 1967 to 1970, by the State-owned company La Générale des carrières et des Mines from 1971 to 2001, and finally by Gécamines and its partners from 2002 up to the present day.

With regard to the question of language in mining companies, and at the Union Minière in particular, it should be remembered that in colonial times, owing to the crucial role that the Robert Williams Company played in the recruitment of workers from South Africa, Botswana, Zimbabwe, and Zambia, English was used as the dominant working language in Southern Katanga [20]. Belgian authorities were concerned about the threat that English represented as illustrated in the following passage quoted in Fabian: "we must with all the means at our disposal fight the spread of any European language other than French...”.

By 1932, most of the British colony workers left Katanga and went back to Rhodesia. This is how the threat of English against French in Katanga disappeared. French then became the main working language especially for skilled workers along with Kiswahili for unskilled workers.

Today, however, the linguistic ecology of mining companies, which are to large extent branches of multinational companies, has changed drastically with the arrival of new investors who use English as the working language with Congolese who speak French and Congolese languages. The shift from French to English is to be accounted for by the fact that, according to Braeckmans et al. [21], after the collapse of mining activities in the DRC and the promulgation of the new mining code in 2002, English-speaking investors revealed themselves more opportunistic in taking risks to start business in the mining sector.

\subsection{Language Practices in Mining Companies in the DRC}

Most of the new Mining Companies operating in the DRC are owned by investors from the following countries: Australia, British Virgin Islands, Canada, China, Great Britain, India, South Africa, Switzerland, and the USA. The workforce of these mining companies is composed of people from diverse nationalities: Americans, Belgians, British, Canadians, Chileans, Chinese, Congolese, Fili- 
pinos, French, Ghanaians, Indians, Indonesians, Kenyans, Nepalese, New Zealanders, Peruvians, South Africans, Swiss, Tanzanians, Zambians, and Zimbabweans.

Apart from the mining companies where French is used as the working language along with Congolese languages, three groups of mining companies have been identified. The data provided below have been collected through interviews and questionnaires.

\subsubsection{Mining Companies Created/Owned by English-Speaking Investors:} The Case of TFM, MMG, Ruashi Mining, KCC, and MUMI

In these companies, languages are distributed as follows:

1) English is used as the corporate language.

It is also used in the following cases:

a) between expatriate managers or supervisors and Congolese supervisors and workers.

b) between expatriate managers or supervisors and foreign supervisors, and in communication with parent company abroad.

2) English, a mixture of English, French and local languages, or English with interpretation in French and local languages: between expatriate managers or supervisors and Congolese workers, between Congolese workers and their foreign co-workers, and in media interviews with top management.

3) English and French or English with interpretation in French: in meetings with top management and in reports and memos.

4) English and Kiswahili: between Congolese workers and transport drivers from abroad or subcontractors.

5) French with interpretation in English or through a Congolese representative of the company: in meetings with local administration and authorities.

6) French, English or French with interpretation in vehicular languages: in training sessions for workers.

7) English, French, and local languages: for written instructions and documentation.

8) Afrikaans, Arabic, Chinese, Congolese languages, Dutch, English, Filipino, French, Hindi, Indonesian, Kibemba, Kinyanja, Korean, Sotho, Shona, Spanish, and Zulu: between employees of the same ethnic background.

Vehicular languages through a representative of the company: in communication with the local population.

\subsubsection{Mining Companies Owned by Indian Investors: The Case of SOMIKA and CHEMAF}

English is used as a corporate language with interpretation in the vehicular languages.

1) Hindi (or any other Indian language): between Indian managers, supervisors, and workers.

2) English is also used in the following situations: between Indian managers or 
supervisors and Congolese and foreign supervisors and workers, in meetings with top management, reports and memos, and in communication with parent company abroad.

3) English and national languages, or a mixture of English and national languages: between Congolese workers and their foreign co-workers and in written instructions and documentation.

4) English with interpretation in French or French through a Congolese representative of the company: in media interviews with top management.

5) English or Kiswahili: between Congolese workers and transport drivers from abroad.

6) English or French with interpretation in Kiswahili or Lingala: in training sessions with workers.

7) French through a Congolese representative of the company: in meetings with local administration and authorities.

8) French, Kiswahili or Lingala: in communication with the local population.

Between employees of the same ethnic background, the same languages mentioned in the first group of mining companies are used.

\subsubsection{Mining Companies Owned by Chinese Investors: The Case of CDM and COMILU}

1) Chinese is used as the corporate language with interpretation in French, Kiswahili, or Lingala.

2) Chinese is also used between Chinese managers, supervisors and workers and in communication with the parent company abroad.

3) Chinese is used with interpretation in English, French or in English, French, Kiswahili or Lingala: between Chinese managers or supervisors and Congolese supervisors or unskilled workers, in meetings with top management, media interviews with top management, and training sessions for workers.

4) English: between Chinese managers or supervisors and foreign workers.

5) Chinese or English and French with interpretation in Chinese: in reports and memos.

6) Chinese with interpretation in French, Kiswahili or Lingala with gestures or a mixture of Chinese, French, English, Kiswahili and Lingala: between Chinese managers or supervisors and Congolese workers.

7) English and Kiswahili: between Congolese workers and their foreign co-workers and with transport drivers from abroad.

8) French with interpretation in Chinese: in meetings with the local administration and authorities.

9) Chinese with translation into French: in written instructions and documentation.

10) Kiswahili, Lingala or any other local language: in communication with the local population.

Between employees of the same ethnic background, the same languages mentioned in the first group of mining companies are used. 


\subsection{Language Beliefs within the Workplaces of Mining Companies}

Language beliefs are widely varied among participants within the workplaces of the mining companies under investigation.

English and Chinese-speaking managers and supervisors are generally ethnocentric about their languages and take it for granted that Congolese workers must do their utmost to comply with their working languages. English-speaking investors stick to the principle that English is used as the global language of international business.

In connection with this belief, Nekvapil and Sherman [22] assert that "the languages used by the expatriates may be perceived as more powerful than the local languages and it is assumed that the local employees will acquire these languages, while the expatriates can allow themselves to function without knowledge of the local languages".

Indian managers, supervisors, and workers adapt themselves quickly to the local languages, namely Kiswahili and Lingala, but not French that they find difficult to learn. And so do Chinese managers, supervisors and workers.

As to Congolese employees, they react differently to the use of corporate languages.

Some of them think that the use of English is a necessity in this age of increased globalization. Some more think that it is an imposition. Others think that it is a barrier to communication, while some others view it as a social problem or an obvious fact.

Congolese employees consider French and national languages as their cultural heritage and they cannot easily accept the imposition of a language like English or Chinese on them even though knowledge of these languages as working languages is a necessity.

Some of them think that the fact that expatriates do not make any effort to speak their languages is a lack of respect for the local people and their culture. Others think that expatriates who are in a small number should try and learn French and national languages instead of imposing them to learn English or Chinese. Some Congolese feel frustrated because their competence at work is undermined by their linguistic deficiencies in the working language.

Yet, in the minds of Congolese employees, English enjoys a higher prestige than French and national languages because it is considered as a resource with more economic value since it provides them with competitive advantages to find better paid jobs and to be promoted to higher positions in work environments where it is used as a working language.

With regard to the learning of languages, Congolese are obliged to learn English for their advancement in the career. Yet, the conditions under which they learn the language are not easy at all, since the learning of languages is sometimes conflicting with the work schedule. Some Congolese learn the language as self-made men. Some expatriates learn Congolese languages on their own initiative without any imposition. 
Translation plays a critical role since all the instructions and the documents written in English or Chinese must be translated into local languages.

\subsection{Some Reflections on and Guidelines for Language Management in Mining Companies in the DRC}

\subsubsection{Some Reflections on Language Management in Mining Companies}

The question of language management in the mining companies operating in the DRC is a delicate one since it involves three different actors with diverging interests.

On the one hand, companies seek to have a working language that can help them reduce at the maximum all kinds of costs and maximize their competitive advantages in creating economic value through enhancement of productivity. They need a corporate language because it reduces the negative effects of language barrier created by linguistic diversity. They are not interested in the linguistic rights of employees.

On the other hand, the government is another powerful actor. It needs to attract investors in offering them some advantages in their business and avoiding to impose them too many constraints. The government does not interfere directly in the functioning of companies. But the government is supposed to protect the interests of its population in favoring their access to good position on the labour market and to protect their rights.

The third actor is the employee who is torn between his right to use his native language and the obligation of using the investors language as a working language which opens him the way to advancement in his career. He can oppose his resistance against the language policy implemented by the company but he has no power to make the company change the decision.

The question to be asked is to know for the interest of which actor language management should be made. It is not easy to design a language management that can satisfy the interests of all the actors. In any case, three options are available for language management in these companies, namely promoting English or Chinese as a corporate language, imposing the use of French and Congolese languages, and implementing reciprocal learning of languages. Each option has its advantages and disadvantages. In any case, a fair and balanced language management would be the implementation of a language policy of the trilingualism English (or Chinese)-French-National language(Kiswahili, Kikongo, Lingala or Ciluba, depending on the linguistic area) since it would take into account the interests of all the actors.

\subsubsection{Some Guidelines for Language Management in Mining Companies}

When taking the decision of starting business in the mining industry in the DRC, investors should be prepared to understand that in this age of increased globalization, their companies use a multilingual workforce and that language skills add value to the employability of the individual and the competitiveness of the companies. They should also understand that the economic value of linguis- 
tic diversity is increasing.

Therefore, they should be prepared to overcome their ethnocentrism based on the global strategy of using English exclusively, or another language like Chinese, within their multilingual workplaces. They should think globally but act locally and adjust to the host country in adapting their global strategy to the local environment in order to reduce resistance from the employees.

They should identify the linguistic resources in conducting linguistic audits before the implementation of any language policy.

They should also take into account the language policy of the country in general and adapt their language strategies to the sociolinguistic mapping of the area in which they operate. It is in this vein that Ludi et al. [23] argue that the language policy of the country or the region where the company is located is part of the context which is going to determine its way of treating languages. As a matter of fact, language questions can bring about work conflicts if they are not well managed. A case in point mentioned by Ludi et al. [23] and Truchot and Huck [24] is that of General Electric Medical Systems, an American multinational company operating in France, which was using documents written in English, making the knowledge of English compulsory for employees. In virtue of French Laws, and especially the 1994 LoiToubon, the employees had to sue the company in court because English was used as a working language. The company had to pay fines and an agreement was reached obliging the company to translate all documents from abroad into French.

For ethical reasons, and in virtue of the Universal Declaration of Linguistic Rights, the respect of the linguistic rights of the employees should be enshrined in the codes of conduct of multinational companies which are required to comply with the rules and laws of the host countries.

The Labour Code of the DRC should stipulate clearly that Congolese employees have the right to use their native languages at work in their country. As a matter of fact, imposing a foreign language to local employees devalues the quality of their work because they express themselves better in their native languages and their competence at work is also likely to be undermined by their language deficiencies. In addition, such an imposition of a foreign language may yield discrimination, exclusion, lack of motivation, linguistic insecurity, anxiety, misunderstandings, errors with risks of accidents, stress and, ultimately, loss of productivity, to name but a few of the negative effects of an imposed language.

The Mining Code of the DRC should stipulate clearly that prospective investors in the mining industry must comply with the language policy of the DRC in order to protect the linguistic rights of Congolese employees.

The Provincial Government of the area where mining companies operate should ensure, through the Provincial Ministry of Mines and the Labour Inspectorate that the linguistic rights of Congolese employees are guaranteed and that they are not left at the mercy of mining companies' language policies.

In order to reduce social tensions, malaise, and linguistic insecurity among 
employees and create a balance between languages, it is better to implement a policy of multilingual communication involving French, English (or any other working language), and one of the national languages used in the area.

English-speaking managers and supervisors should strive to speak local languages, even small talk, as a symbolic effort to communicate with the local people. A resolute unwillingness to speak the local languages may be seen as a conspicuous sign of contempt to local people.

Congolese who seek employment in multinational companies and international organizations should, on the other hand, be prepared to invest themselves in developing or improving proficiency in English, Chinese or any other working language which is an asset for their advancement in their career.

Mining Companies should forge links with local universities for cooperation with them in the search of expertise in language management issues like language audits, specialized language training, translation and interpretation in the same way as this cooperation has been launched in the geological domain.

In the same vein, a multifaceted interface should be developed between mining companies and local academic institutions for mutual interests in other domains in which the local universities and colleges can provide expertise like medicine, public health, agriculture, civil and mining engineering, chemistry, metallurgy, electro mechanics, electricity, laboratory, industrial engineering, accounting, economics, law, communication, language and business, nutrition, computer science, English, French, and African languages. These academic institutions can in return place their graduates for employment and their undergraduates for training in the mining companies.

\section{Conclusion}

In this age of increasing globalization, languages and cultures are coming in greater contact with each other than ever before. Admittedly, the need to communicate effectively in the linguistically diverse environments of mining companies requires some degree of linguistic commonality. The fact of the matter is that English has been internationally recognized as a global language of business communication. However, as important as English is for global communication, insights gained from mining companies operating in the DRC have revealed that English, or any other working language, is not enough for the many communication needs within the multilingual workplaces of these mining companies. Other languages are also valuable. It is advisable that the Congolese government takes steps to regulate language practices into the language policies of the mining companies in order to avoid a mess in language practices or a babel in business. Otherwise, in the long run, the country will be left to the mercy of all languages imposed as working languages and which are spreading foreign cultures to the detriment of the local culture. The government should require of these companies to comply with the laws of the country because multinational companies are known to have the bad reputation of reducing the sovereignty of States and of 
complying only with their Code of Business Conduct. Language management in these mining companies should involve all the actors in order to develop a well-balanced language policy within the workplaces of the mining companies. Although the adoption of a common language is a necessity for the internal coordination of activities within the mining companies, multilingual communication ought to be valued for the efficiency of communication and enhancement of productivity.

\section{Conflicts of Interest}

The authors declare no conflicts of interest regarding the publication of this paper.

\section{References}

[1] Reeves, N. and Wright, C. (1996) Linguistic Auditing. Multilingual Matters, Clevelon.

[2] Marschan-Piekkari, R., et al. (1997) Language: The Forgotten Factor in Multinational Management. European Management Journal, 15, 591-598.

https://doi.org/10.1016/S0263-2373(97)00038-8

[3] Feely, A.J. and Harzing, A.W. (2002) Forgotten and Neglected Language: The Orphan of International Business Research. The 62nd Annual Meeting of the Academy of Management, Denver, 9-14 August 2002. http://harzing.com/download/orphan.pdf

[4] Jomo, K.S. (2006) Globalization under Hegemony. The Changing World Economy. Oxford University Press, Oxford.

[5] Dhir, K.S. and Goke-Pariola, A. (2002) The Case for Language Policies in Multinational Corporations. Corporate Communications: An International Journal, 7, 241-251. https://doi.org/10.1108/13563280210449822

[6] Heller, M. (2005) Language, Skill and Authenticity in the Globalized New Economy. Noves SL. Revista de Sociolinguistica. http://www.gentcat.cat/llengua/noves

[7] Coulmas, F. (1992) Sociolinguistics: The Study of Speakers' Choices. Cambridge University Press, Cambridge. https://doi.org/10.1017/CBO9780511815522

[8] Marschan-Piekkari, R., et al. (1999) In the Shadow: The Impact of Language on Structure, Power and Communication in the Multinational. International Business Review, 8, 421-440. https://doi.org/10.1016/S0969-5931(99)00015-3

[9] Harzing, A.W.K. and Pudelko, M. (2013) Language Competencies, Policies and Practices in Multinational Corporations: A Comprehensive Review and Comparison of Anglophone, Asian, Continental, European Nordic MNCs. Journal of World Business, 48, 87-97. https://doi.org/10.1016/j.jwb.2012.06.011

[10] Sorensen, E.S. (2005) Our Corporate Language Is English: An Exploratory Survey of 70 DK-Sited Corporations' Use of English. Master's Thesis, Aarhus School of Business, Aarhus.

[11] Miller, S. and Jensen, A. (2009) Language Choice and Management in Danish Multinational Companies: The Role of Common Sense. Sociolinguistica, 23, 86-103. https://doi.org/10.1515/9783484605879.86

[12] Kankaraanta, A. and Louhiala-Salminem, L. (2010) English?-Oh, It's Just Work: A Study of BEL Fusers' Perceptions. English for Specific Purposes, 29, 204-209. 
https://doi.org/10.1016/j.esp.2009.06.004

[13] Harzing, A.W.K., et al. (2010) Babel in Business: The Language Barrier and Its Solutions in the HQ-Subsidiary Relationship. Journal of World Business, 46, 270-297.

[14] Grigore, L.N. (2006) Managing Language Problems-A Key Source of Competitive Advantage in the Global Business Environment. Synergy, 2, 50-59.

[15] Tange, H. and Lauring, J. (2006) What Kind of English Is That? Dilute and Contained Communication in the Workplace. NIC 2006-Questions of Power in Intercultural Communication.

[16] Thomas, C.A. (2007) Language Policy in Multilingual Organizations. Working Papers in Educational Linguistics, 22, 81-104.

[17] Didiot-Cook, H., et al. (2000) Language Needs in Business, a Survey of European Multinational Companies. CEMS Inter-Faculty Group for Languages Joint Study Project. Saint Galien.

[18] Van den Born, F. and Peltokorpi, V. (2010) Language Policies and Communication in Multinational Companies. Journal of Business Communication, 47, 97-118. https://doi.org/10.1177/0021943610364515

[19] Luo, Y. and Shenkar, O. (2006) The Multinational Corporation as a Multilingual Community: Language and Organization in a Global Context. Journal of International Business Studies, 37, 321-339.

[20] Fabian, J. (1986) Language and Colonial Power. University of California Press, Oakland.

[21] Braeckman, C., et al. (1998) KABILA prend le pouvoir. GRIP, Bruxelles.

[22] Nekvapil, J. and Sherman, T. (2009) Language Management in Contact Situations: Perspectives from Three Continents. Francfurt am Main: Peter Lang.

[23] Lüdi, G., et al. (2009) La gestion du plurilinguisme au travail entre la philosophie de l'entreprise et les pratiques spontanées. Sociolinguistica, 23, 32-52.

[24] Truchot, C. and Huck, D. (2009) Le traitement des langues dans les entreprises. Sociolinguistica, 23, 1-31. 